\title{
Integrated Pest Management for Rodent in Buildings
}

\author{
Abd El Aleem Saad Soliman Desoky* \\ Department of Plant protection (Agriculture Zoology), Sohag University, Egypt
}

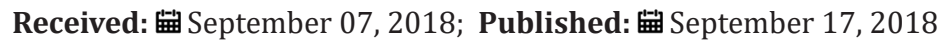

*Corresponding author: Abd El Aleem Saad Soliman Desoky, Department of Plant protection (Agriculture Zoology), Faculty of Agriculture, Sohag University, Egypt

\section{Abstract}

The objectives of the study are to provide an integrated control program for rodents in buildings and to clarify the most important preventive methods that can be used in the control process and to make some important observations when the application of control methods such as mechanical control, biological and chemical to get the best anti-rodent program inside buildings.

Keywords: Integrated Control Program; Preventive Methods; Control Process; Anti Rodent

\section{Introduction}

Rats and mice can be a major pest problem in buildings. They damage food, books, documents, and clothing. Damage to a structure occurs when rats and mice gnaw on structural components, including wiring, wood, and plastics. The gnawing on wire insulation can result in electrical shorts and fires. Rodents have also been implicated in the spread of dangerous human diseases. In short, structural risks, health risks, and a general lowering of environmental quality accompany any rodent infestation. All rodents require food, shelter, and water. The shelter provides protection from predators, inclement weather, and a favorable place to bear and rear their young. Although rodents require water, those water requirements vary greatly by species. Because rodent food and cover (i.e., vegetation) can be influenced by human activities, there has been considerable development of strategies to reduce populations and damage by manipulating vegetation [1].

Follow the tips in the sections below and you will be one step closer to keeping your home permanently free of rats and mice (SRC)

\section{Preventive Methods}

The most important steps in controlling rodents are preventive methods because prevention is better than control. The following means:

a) Healthy buildings should be constructed to prevent the entry of mice and rats. b) In occupied buildings, all possible access areas should be identified by rodents.

c) Repair / seal any cracks or holes small diameter or inch or larger in the foundation, walls.

d) Repair broken windows and doors - Make sure that the door seals are tight for any inhabited buildings.

e) Place the wire on all building windows.

f) All edible foods (lunch and snacks) will be stored in rodent-resistant containers and not in office drawers.

g) Cracked or unusual food will be cleaned and removed from the intake area at the end of each day.

h) Garbage containers are emptied in the dining areas daily or have narrow blankets.

i) There will be no garbage dumps in the uninhabited buildings.

j) The external garbage areas will remain clean and devoid of organic debris on the ground.

k) Remove rodent attractions such as food or shelter by ensuring that the food is stored safely and that the surrounding environment is clean.

l) Rinse food and beverage containers before disposing or recycling. 
m) Keep at least two feet between bushes, shrubs, fences and buildings. Also, remove the limb within 3 feet of the structure or ceiling.

n) Keep firewood away from the ground and away from structures as much as possible to mitigate shelter opportunities.

o) Fruit trees will be free of fruit that has fallen to the ground during summer and fall.

p) Birds, squirrels and other wildlife will not be fed within 200 feet of any building in the province.

q) Prevent the entry of animals into warehouses and houses.

r) Keep stove tops clean and free of food scraps.

s) Separate your home from paper, fabric, and any similar materials that attract rodents to nest.

4. Methods of Treatment

\section{Mechanical Control}

\section{Using Traps}

Using traps instead of rodent poisons gives you clear confirmation of a captured rodent and allows you to better gauge the effectiveness of treatment. You are also able to dispose of rodents immediately rather than dealing with the foul odor of rotting carcasses from poisoned rodents inside your walls or otherwise out of reach. Most important, using traps allows you to avoid rodenticides, which pose a greater threat of exposure to children, pets, and non-target wildlife, including natural predators (SRC).

\section{Traps Description}

i. Live Animal Trap: This is a catch and release system that avoids killing a rat or mouse. Some states prohibit releasing rodents into the wild. The Center for Disease Control (CDC) warns that captured rats or mice might urinate and increase risk of spreading disease. Muhammad Sarwar (2015)

ii. Snap Trap: This is the oldest type of trap and uses a springloaded bar to kill a rodent on contact. Some modern snap traps prevent risk to children and pets by enclosing the device in a plastic box.

iii. Multiple Catch Live Mouse Trap: This is a catch and release system that allows for capture of multiple mice.

iv. Glue Trap: Glue traps are not recommended because the adhesive plate that is used to capture rodents can also trap birds, baby animals, lizards, and even pets. These traps also cause undue suffering to rodents. The CDC warns that captured rats or mice might urinate and increase the risk of spreading disease. Enclosure boxes are plastic boxes that can fit a single snap trap, sometimes more, to provide an additional layer of protection for kids and pets. These boxes also hide the dead rodent, making for easier disposal of rodent, and can be re-used (SRC)

v. Electronic Trap: This battery-powered trap delivers an electric shock that kills rodents quickly. This is a newer type of trap, and models are available for both rats and mice.

vi. Important Notes:

a) Be sure to place traps in locations where children and pets cannot access them or place traps in safety enclosure boxes.

b) Place the trap sideways next to the walls.

c) Do not place the trap continuously.

d) Wash the trap after the fishing process.

e) Remove rodents by using traps be cautious with live traps as rodents might urinate which increases the risk of spreading disease.

f) Use gloves when disposing of dead rodents, nests, or any nesting material.

g) Spray the dead rodent or nesting material with a disinfectant solution and allow them to soak for 5 minutes before disposing rodent or materials in a secure plastic bag.

h) Spray and wipe up the area surrounding dead rodent or nesting material with a disinfectant.

i) Place the plastic bag with rodent or nesting material into another plastic bag along with any wipes or rags that were used to sanitize the surrounding area.

j) Be sure to wash your hands thoroughly with soap and water (SRC).

\section{Destruction of Burrows}

Pruning both for adult trees or foliage with disposal of pruning products so as not to be a cache of mice to form a nest on these wastes.

\section{Biological Control}

Using Natural predators such as cats can help to control rodent populations by feeding on rats and mice. (SRC).

\section{Chemical Control}

\section{Conditions to be Available Before Rodent Control}

a) The control process should be carried out in case of the presence of mice or their effects.

b) You must know the type of rodent present because each type has a control method [2]. 
c) You should use bra-baiting so that avoidance of poison bait does not occur.

d) The control should be performed when the population density is as low as possible [3].

e) The food available should be as low as possible.

f) The control method varies depending on the location and food available.

g) You must use a bait different from the food available in the place.

h) Use attractants if necessary.

\section{Using Rodenticides}

Rodenticides consist of different types of poisons used to kill rodents. Rodenticide baits can be lethal for any mammal or bird that ingests them and are not only poisonous for rodents. As a result, all baits pose a high risk of poisoning for non-target animals that might eat the bait or consume a poisoned rat or mouse [4].

a) The use of rodenticides must be used with preventive measures such as gloves.

b) If you choose to use rodenticides, you should be ready to deal with these potential consequences:

c) Rodents are likely to die in locations where they cannot be retrieved

d) The smell of a dead animal will persist for several weeks to several months.

e) Always read and follow the label instructions on the pesticide product. The label is the law and you could be liable for any damage resulting from not following the label instructions.

f) Indoors, only place rodenticide bait stations in locations that are completely inaccessible to children and pets-inside walls, under heavy appliances, or in enclosed crawlspaces [5].

g) It is best to use anticoagulants because they are environmentally safe [6]. h) Passage on the bait's stations in the early morning or before sunset.

i) The lids of all bait stations must be securely.

j) All bait stations should be numbered, and their location marked on a simple floor plan map.

k) Bait stations should be inspected during every service visit for monitoring purposes and to ensure stations are not providing harborage to non-target pests [7].

l) When dead mice must be disposed of quickly because they have dangerous external parasites.

m) Once all signs of rodents are gone, remove bait stations promptly by placing in a secure plastic bag. (UCDIO) [8].

\section{References}

1. Barras SC, TW Seamans (2002) Habitat management approaches for reducing wildlife use of airfields. Proceedings of the Vertebrate Pest Conference 20: 309-315.

2. Witmer GW, MW Fall, LA Fiedler (1995) Rodent control, research needs, and technology transfer. International wildlife management congress pp. 16-26.

3. Buckle AP, RH Smith (1994) Rodent pests and their control. CAB International, Wallingford, UK.

4. Buckle AP (1999) Rodenticides their role in rodent pest management in tropical agriculture. In: Singleton GR, Hinds LA, Leirs H, Zhang Z(Eds), Ecologically based Management of Rodent Pests. ACIAR, Canberra, pp. 163-177.

5. Desoky ASS (2014) Strategies of Rodent Control Methods at Airports, Global Journal of Science Frontier Research.

6. Desoky ASS (2016) Rodenticides (Anticoagulant). International Journal of Research Studies in Zoology, EPA, Environmental Protection Agency 2(3): $1-6$.

7. Desoky ASS (2007) Management strategies for rodents within different ecosystems. M Sc Thesis, Fac Agric Assiut Univ pp. 124.

8. Muhammad Sarwar (2015) The Rodents (Mammalia: Rodentia)Gnawing Away on Crops and Options for the Integrated Pest Management at Field. American Journal of Marketing Research SRC, Safe Rodent Control UCDIO, University of California, USA, 1(3): 136-141.
(C) (i) This work is licensed under Creative

To Submit Your Article Click Here:

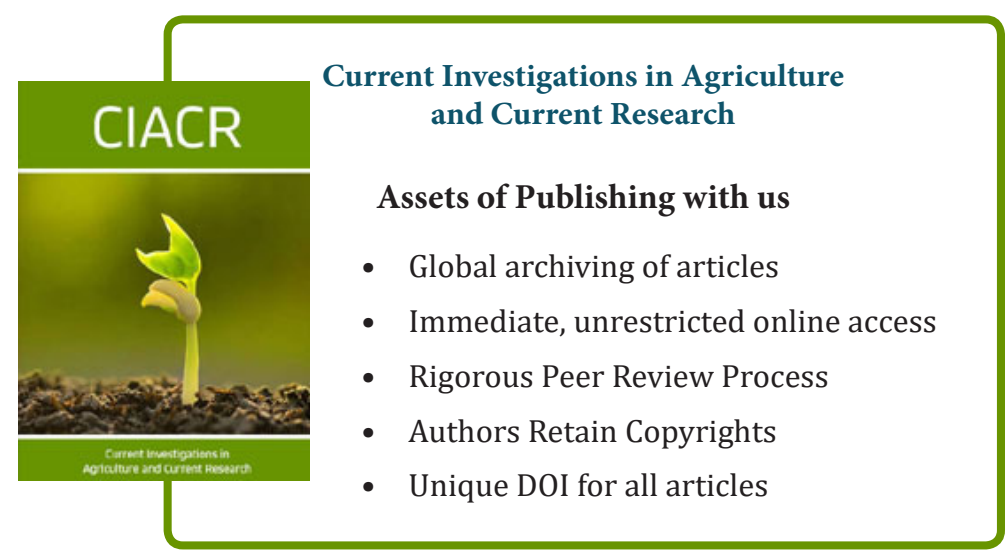

